\title{
Capillary hemangioma of the scrotum mimicking an epididymal tumor: Case report
}

\author{
Antonio Vavallo ${ }^{1}$, Francesco Lafranceschina ${ }^{1}$, Giuseppe Lucarelli ${ }^{1}$, Carlo Bettocchi ${ }^{2}$, \\ Pasquale Ditonno $^{2}$, Michele Battaglia ${ }^{2}$, Francesco Paolo Selvaggi ${ }^{1}$ \\ ${ }^{1}$ Casa Bianca Hospital (GVM), Cassano delle Murge, Bari, Italy; \\ ${ }^{2}$ Urology, Andrology and Kidney Transplantation Unit, Department of Emergency and Organ Transplantation (DETO), \\ University of Bari, Italy.
}

\begin{abstract}
Summary We report a case of capillary hemangioma of the scrotum. A 52-year-old male presented with a left scrotum swelling that had arisen suddenly two months before. Scrotal ultrasound revealed a dishomogeneous mass in the left scrotum. The mass demonstrated blood flow in the color Doppler mode. Scrotal mass excision was performed. Pathological evaluation revealed a capillary hemangioma.
\end{abstract}

KEY WORDS: Capillary; Hemangioma; Scrotum.

Submitted 3 October 2014; Accepted 31 October 2014

\section{INTRODUCTION}

Scrotal hemangioma is a very rare benign vascular neoplasm, mostly seen in children and young adults and comprises less than $1 \%$ of all hemangiomas (1).

Malignant tumors of the epididymis constitute 25\% of the tumors of this area (2). In the current study, we report a case of capillary hemangioma of the left scrotum, which mimicked an epididymal tumor, and discuss the diagnostic and therapeutic problems.

\section{Case report}

A 52 years old man referred to our department for painless enlargement in the left hemiscrotum for two months. Personal and familiar history were unremarkable. The patient denied any history of fever, scrotal trauma or epididymitis. At physical examination, the mass was discriminated from the testis, but not from epididymis and spermatic cord. The patient had a normal blood cell count and urinalysis. Laboratory examinations, including relevant tumor markers, particularly $\alpha$-fetoprotein and $\beta$-human chorionic gonadotrophin, were normal. Scrotal ultrasound revealed a dishomogeneous mass, lying on the border between epididymal tail and lower pole of the left testis without any disruption of the architecture of the testicular parenchyma. Color Doppler sonography showed increased blood flow with- in the lesion. The patient was diagnosed with a suspected epididymal neoplasm and a left inguinal approach was performed. The mass was dissected with testicular and epididymal sparing surgery and found to be a nodular, dark red conglomerate of distended blood vessels measuring $7 \times 5 \times 2 \mathrm{~cm}$. The mass was not attached to the testis or the spermatic cord, but was adherent to the epididymis. Pathological examination identified a capillary hemangioma and immunohistochemical staining for CD31, actin, S100 protein and Ki67 confirming the vascular nature of this tumor. On the basis of the morphological characteristics and immunohistochemical findings, the diagnosis of scrotal capillary hemangioma was rendered. At the last follow-up, 12 months after the operation, the patient was healthy without any clinical evidence of complication or recurrence.

\section{Discussion}

Hemangiomas are benign vascular tumors, which may develop in any part of the body and they are most common in the musculoskeletal system, liver and spleen. Hemangiomas are classified into capillary, cavernous, arteriovenous, venous and mixed subtypes and may be composed of vessels whose walls are abnormal and cannot be identified as arterial or venous (3). The occurrence of capillary hemangioma in the scrotum is rare and scrotum enlargement, with or without tenderness, is the chief presenting symptom. Only a few number of articles describing intrascrotal hemangioma have been reported. An interesting point of our case is the age; our patient was a 52-year-old male and, as far as we know, this is the first case in which the patient is older than 50 years in the literature. Ultrasonography is useful for diagnosing scrotal hemangiomas, but rarely definitive. It can determine the extent of the lesion, delineate its relationship with adjacent structures, demonstrate the nature of the mass and help plan therapy. In sonography, hemangiomas vary from hypoechoic to hyperechoic, or they may be heterogeneous. Color Doppler may demonstrate blood flow within these lesions but the absence of flow 


\section{Figure 1.}

Macroscopic specimen of the dissected mass, which appeared as a nodular, dark red conglomerate of distended blood vessels.

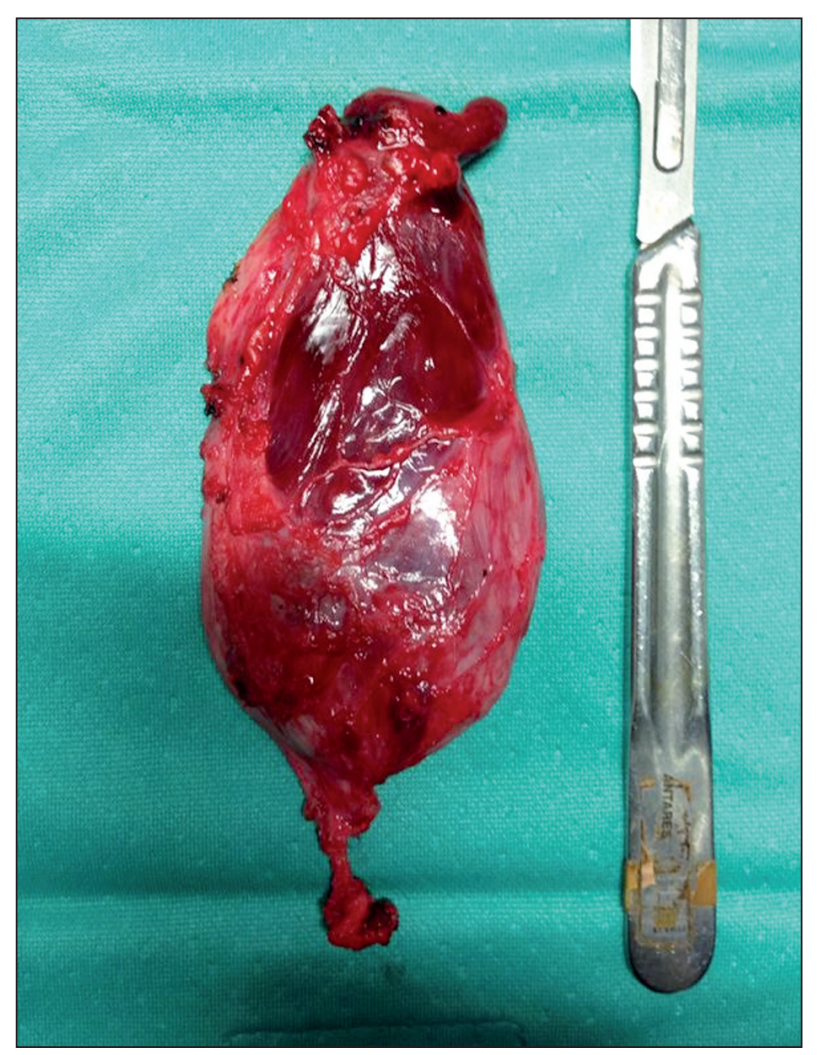

does not rule out the presence of the lesions. Magnetic Resonance Imaging (MRI) may provide more useful information for differentiation. When the diagnosis is established, eradication of the lesion is recommended and the lesion must be complete removed to avoid recurrence. Since it is impossible to differentiate a hemangioma from a malignant tumor before the operation, intra-operative frozen section examination may be requested as tumor enucleation with testicular and epididymal sparing surgery is considerate adequate.

\section{Conclusion}

In summary, capillary scrotal hemangioma is a very rare neoplasm with different morphologies having in common an infiltrative growth pattern. Clinical and radiologic findings may preoperatively suggest a vascular tumor; however any scrotal solid masses of uncertain diagnostic significance require surgical approach to define the nature by hystological examination.

\section{REFERENCES}

1. Lin CY, Sun GH, Yu DS, et al. Intrascrotal hemangioma. Arch Androl. 2002; 48:259-65.

2. Dell'Atti L. Ultrasound diagnosis of unusual extratesticular mass: case report and review of the literature. Arch Ital Urol Androl. 2013; 85:41-3.

3. Rastogi R. Diffuse cavernous hemangioma of the penis, scrotum, perineum, and rectum- A rare tumor. Saudi J Kidney Dis Transpl. 2008; 19:614-8.

\section{Correspondence}

Antonio Vavallo, MD (Corresponding Author)

antoniovavallo@hotmail.com

Francesco Lafranceschina, MD

Giuseppe Lucarelli, MD

Francesco Paolo Selvaggi, MD

Casa Bianca Hospital (GVM)

Cassano delle Murge, Bari, Italy

Carlo Bettocchi, MD

Pasquale Ditonno, MD

Michele Battaglia, MD

Urology, Andrology and Kidney Transplantation Unit, Department of Emergency and Organ Transplantation (DETO), University of Bari

Piazza G. Cesare 11 - 70124 Bari, Italy 